\title{
PENGARUH PEMBELAJARAN PEMBERDAYAAN BERPIKIR MELALUI PERTANYAAN DIPADUKAN STRATEGI DISCOVERY LEARNING (PBMP- SDL) TERHADAP KEMAMPUAN BERPIKIR KRITIS SISWA
}

\author{
Rosyana $^{1,2}$ \\ Poedjiastoeti $^{3}$ \\ Rahayu $^{3}$ \\ ${ }^{1}$ Mahasiswa Prodi Pendidikan Sains Pascasarjana Universitas Negeri Surabaya \\ ${ }^{2}$ Guru IPA SMP Al Hikmah Surabaya \\ ${ }^{3}$ Dosen Pascasarjana Prodi Pendidikan Sains Universitas Negeri Surabaya \\ e-mail:iraikadua@yahoo.com
}

\begin{abstract}
This research aimed to describe the effect of the TEQ - DLS learning on critical students' critical thinking skill. This research was conducted in two stages, developed teaching learning material followed by the implementation phase of learning in the classroom. This research was a quasi experimental design with one-group pretest-posttest design and the subject of this research was 34 eighth grade students of SMP Al Hikmah Surabaya. Research data collection was taken through observation, tests, questionnaires, and documentation. The results of research data validation were analyzed descriptively. The empirical analysis includes the calculation of validity, reliability and sensitivity of the items test instrument. Critical thinking scores were analyzed using normalized gain and paired t-test to determine the effect of TEQ - DLS on learning outcomes of students. The results were obtained as follows: the learning implementation indicated good category. T-paired test on students' critical thinking results showed sig (2-tailed) = 0.00 so there were significant differences in students' critical thinking skills after learning. Students score had increased with normalized gain $=0.67$ medium category $(0,3 \leq(<g\rangle) \leq 0$,7). Students' completeness viewed from critical thinking indicator as big as $88.24 \%$. Research was concluded that the TEQ-DLS learning has an effect significantly in improving students' critical thinking skills.
\end{abstract}

\begin{abstract}
Abstrak: Penelitian ini bertujuan untuk mendeskripsikan pengaruh pembelajaran PBMP-SDL terhadap kemampuan berpikir kritis siswa. Penelitian dilaksanakan dalam dua tahap, yaitu tahap pengembangan perangkat pembelajaran dilanjutkan dengan tahap implementasi pembelajaran di kelas. Jenis penelitian ini adalah kuasi eksperimen dengan rancangan one group pretest-postest design dan subyek 34 siswa kelas VIII SMP Al Hikmah Surabaya. Pengumpulan data penelitian diambil melalui observasi, tes, angket, dan dokumentasi. Data hasil validasi perangkat pembelajaran dianalisis secara deskriptif. Analisis empiris instrumen tes meliputi perhitungan validitas, reabilitas dan sensitivitas butir soal dari hasil belajar siswa. Skor berpikir kritis dianalisis menggunakan gain ternormalisasi dan uji t-berpasangan. Hasil penelitian menunjukkan bahwa keterlaksanaan pembelajaran menunjukkan kategori baik. Hasil uji t- berpasangan terhadap kemampuan berpikir kritis siswa pada materi zat aditif makanan menunjukkan sig (2-tailed) $=0,00$ artinya terdapat perbedaan secara signifikan setelah pembelajaran. Skor siswa mengalami peningkatan dengan gain ternormalisasi $=0,67$ berkategori sedang $(0,3 \leq(<g>) \leq 0,7)$. Ketuntasan siswa ditinjau dari indikator berpikir kritis sebesar $88,24 \%$. Kesimpulannya pembelajaran PBMP-SDL berpengaruh secara signifikan meningkatkan kemampuan berpikir kritis siswa.
\end{abstract}

Kata-kata Kunci: PBMP, discovery learning, berpikir kritis

\section{PENDAHULUAN}

Upaya meningkatkan kualitas pendidikan tidak. Terlepas dari upaya memberdayakan potensi siswa sebagai peserta didik dan sebagai masyarakat belajar. Hal ini sesuai dengan amanat Pasal 3 UU No. 20 Tahun 2003 tentang Sistem Pendidikan Nasional bahwa tujuan pendidikan nasional, yaitu mengembangkan potensi peserta didik agar menjadi manusia yang beriman dan bertakwa kepada Tuhan Yang Maha Esa, berakhlak mulia, sehat, berilmu, cakap, kritis, kreatif, mandiri, dan menjadi warga negara yang demokratis dan bertanggung jawab (Depdiknas, 2003).

Shukor dalam Muhfahroyin (2009) menyatakan bahwa untuk menghadapi perubahan dunia yang begitu pesat adalah dengan membentuk budaya berpikir kritis di masyarakat. Oleh karena itu hendaknya prioritas utama dari upaya memberdayakan potensi siswa adalah mendidik siswa tentang bagaimana cara belajar dan berpikir kritis, tidak hanya sekedar memperoleh nilai kognitif.

Berpikir kritis merupakan suatu keharusan dalam usaha menyelesaikan masalah, membuat keputusan dan menganalisis asumsi-asumsi. Berpikir kritis diterapkan kepada siswa untuk belajar memecahkan masalah secara sistematis, inovatif, dan mendesain solusi yang mendasar. Melalui berpikir kritis siswa menganalisis apa yang mereka 
pikirkan, mensintesis informasi, dan menyimpulkan (Rehena dan Tumbel, 2010).

Mengacu pada standar kompetensi (SK) dan kompetensi dasar (KD) pada tingkat SMP disebutkan bahwa Ilmu Pengetahuan Alam (IPA) berkaitan dengan cara mencari tahu tentang alam secara sistematis, sehingga IPA bukan hanya penguasaan kumpulan pengetahuan kognitif yang meliputi fenomena-fenomena, konsepkonsep, atau hukum-hukum dasar saja tetapi juga merupakan suatu proses penemuan. Pendidikan IPA diharapkan dapat menjadi sarana bagi peserta didik untuk mempelajari diri sendiri dan alam sekitar, serta prospek pengembangan lebih lanjut dalam menerapkannya di dalam kehidupan sehari-hari (Depdiknas, 2006).

Materi kimia untuk tingkat SMP, pada Kurikulum KTSP tercakup dalam mata pelajaran IPA. Hasil pertemuan MGMP IPA Surabaya tahun 2007 menunjukkan bahwa umumnya materi kimia yang disampaikan masih berorientasi pada pemahaman konsep, belum dirancang dan dilaksanakan secara sengaja untuk pemberdayaan keterampilan berpikir siswa. Hal itu disebabkan karena tidak semua guru kimia di tingkat SMP berlatar belakang atau berkualifikasi mata pelajaran kimia, namun mereka masih mau berusaha mengajar kimia dari sisi penguasaan konsep, sehingga mereka belum memahami perangkat pembelajaran kimia yang berorientasi pada pemberdayaan berpikir tinggi.

Pemberdayaan Berpikir Melalui Pertanyaan (PBMP) merupakan pola pembelajaran IPA di SMP yang dikembangkan oleh Corebima sejak 1985-1990. Pola pembelajaran ini sangat berpotensi memberdayakan kemampuan berpikir siswa seperti yang dilaporkan Corebima dkk (2000, 2001, 2004, 2005, 2006). Ciri utama PBMP adalah ini tidak ada proses pembelajaran yang berlangsung secara informatif, seluruhnya dilakukan melalui rangkaian atau jalinan pertanyaan yang telah dirancang secara tertulis. Pertanyaan tentang hal yang sama, dapat diulang dan dirumuskan dari sudut pandang berbeda-beda. Melalui pembelajaran dengan PBMP ini diharapkan dapat dikembangkan kemampuan berpikir kritis, yang merupakan salah satu ciri dari berkembangnya penalaran formal (Zubaidah dkk, 2001).

Crown (1989) mengemukakan bahwa kemampuan berpikir kritis dapat dikembangkan melalui berbagai aktivitas, diantaranya melalui penciptaan pertanyaan. Penciptaan pertanyaan tersebut dapat dilakukan bersamasama guru dan siswa yang tidak dapat terjadi secara otomatis. Guru harus mempersiapkannya, baik untuk dirinya sendiri maupun untuk siswanya. Guru harus menjadi katalisator dalam penciptaan pertanyaanpertanyaan. Pertanyaan-pertanyaan yang bersifat terbuka dan divergen akan menimbulkan respon dari siswa dan dapat menunjang perkembangan berpikir kritis.

Pembelajaran dengan PBMP dapat menjembatani hal-hal yang telah dipaparkan sebelumnya. Siswa aktif menjawab pertanyaan-pertanyaan dalam pola PBMP, di samping itu ternyata hal tersebut akan memacu timbulnya pertanyaan-pertanyaan. Hal ini nampaknya berhubungan dengan semakin berkembangnya penalaran siswa. Pelaksanaan pembelajaran IPA berupa PBMP ternyata sejalan dengan premis yang menyatakan bahwa siswa dapat belajar lebih banyak jika guru tidak banyak mengajarkan materi. Menurut Corebima dkk (2000), premis tersebut merupakan dasar teknik pembelajaran kooperatif yang dikembangkan oleh Schamel dan Ayres (1992).

Menurut Bruner (1967) discovery learning atau belajar penemuan adalah metode mengajar yang mengatur pengajaran sedemikian rupa sehingga anak memperoleh pengetahuan yang sebelumnya belum diketahuinya itu tidak melalui pemberitahuan, melainkan sebagian atau seluruhnya ditemukan sendiri. Dengan demikian dalam pembelajaran dengan penemuan, siswa dapat memperoleh pengetahuan dari pengalamannya menyelesaikan masalah bukan melalui informasi dari guru. Belajar penemuan dapat mengasah kemampuan berpikir kritis siswa, karena siswa belajar penemuan berbasis inkuiri, teori pembelajaran konstruktivisme sehingga dapat menyelesaikan masalah berdasarkan pengalaman dan pengetahuannya (Arends, 2012).

Materi zat aditif dalam makanan merupakan materi yang menarik bagi siswa karena materi ini bersifat kontekstual. Materi ini disampaikan di tingkat SMP kelas VIII. Pada materi ini siswa diharapkan dapat menyebutkan dan memahami zat aditif dalam makanan yang dijumpai dalam kehidupan sehari-hari. Lebih jauh lagi, dengan mempelajari materi ini diharapkan siswa dapat mengidentifikasi bahan kimia yang sering dijumpai dalam makanan sehingga siswa dapat lebih selektif mengkonsumsi makanan. Oleh karena itu perlu dilakukan alternatif metode pembelajaran yang berpusat pada siswa agar siswa dapat memperoleh pengalaman langsung, mencari tahu dan mengaplikasikan materi yang diperoleh dalam kehidupan sehari-hari sekaligus dapat memberdayakan kemampuan berpikir kritis siswa. Hal ini dapat diatasi dengan mengajar menggunakan pembelajaran dengan PBMP yang dipadukan dengan strategi discovery learning.

Pola pembelajaran dengan PBMP memiliki kelebihan dapat melatih berpikir kritis siswa dengan konsep yang runtut dan terarah, dan siswa menemukan sendiri konsep tersebut melalui aktivitas -lakukan dan jalinan pertanyaan pada fase — pikirkan dan — refleksi, namun kelemahannya pertanyaan-pertanyaan yang diajukan bukan berasal dari siswa melainkan dipandu dari guru dan siswa dapat dengan mudah menemukan jawaban di buku sumber. 
Strategi discovery learning memiliki kelebihan yakni siswa dapat menemukan sendiri pengetahuannya, namun kelemahannya untuk materi tertentu yang bersifat abstrak siswa perlu dibimbing dalam proses penemuannya agar tidak terjadi miskonsepsi.

Berdasarkan kelebihan PBMP yang yang dapat melatih kemampuan berpikir siswa dengan konsep yang runtut dan terarah, maka pada penelitian ini akan dikembangkan pola pembelajaran PBMP untuk melatih berpikir kritis siswa dalam memperoleh konsep zat aditif dalam makanan yang benar. Untuk menutupi kelemahan PBMP, seluruh pertanyaan dan aktivitas pada LKS diarahkan untuk ditemukan jawabannya melalui discovery learning sehingga siswa dapat menemukan dan membangun sendiri pengetahuannya sehingga siswa tidak hanya menemukan jawaban melalui buku siswa saja namun siswa dapat menggunakan penalaran untuk menjawab seluruh pertanyaan. Hal ini akan dapat meningkatkan kemampuan berpikir kritis siswa.

Hasil penelitian pada siswa kelas VIII-I SMP AL Hikmah Surabaya tahun ajaran 2011/2012 menunjukkan bahwa kemampuan berpikir siswa kelas VIII-I masih rendah, yakni rata-rata 52,14. Siswa belum terlatih untuk berpikir kritis. Melalui pola pembelajaran PBMP, terjadi peningkatan hasil belajar siswa kelas VIII-I pada materi zat aditif dalam makanan menjadi 90,14 (Rosyana, 2013).

Berdasarkan latar belakang di atas akan dilakukan penelitian tentang pengaruh pembelajaran Pemberdayaan Berpikir Melalui Pertanyaan dipadukan strategi Discovery Learning (PBMP-SDL) terhadap keterampilan berpikir kritis pada pokok bahasan zat aditif dalam makanan di kelas VIII SMP Al Hikmah Surabaya tahun ajaran 2012/2013.

\section{METODE PENELITIAN}

Jenis penelitian ini adalah kuasi eksperimen (eksperimen semu) dengan rancangan penelitian menggunakan pola dasar "One Group Pretest and Posttest Design" yang dikembangkan oleh Campbell and Stanley. Sebelum mengikuti pola pembelajaran yang dikembangkan, siswa diberi pretest untuk mengetahui kemampuan awal siswa sebelum mengikuti pembelajaran. Setelah mengikuti pembelajaran siswa diberi postest untuk mengetahui kemampuan berpikir kritis dan hasil belajar siswa.

Subyek penelitian ini adalah 34 siswa kelas VIII SMP Al Hikmah Surabaya tahun pelajaran 2012/2013 yang terdiri dari 16 siswa putra dan 18 siswa putri untuk penerapan pola pembelajaran PBMP-SDL. Instrumen penelitian ini lembar observasi keterlaksanaan pembelajaran, lembar penilaian hasil belajar dan kemampuan berpikir kritis. Teknik pengumpulan data melalui observasi, tes, angket, dan dokumentasi.

Teknik analisis data yang digunakan meliputi: 1)
Analisis hasil validasi perangkat pembelajaran menggunakan analisis deskriptif yakni dengan mencari rata-rata skor yang diperoleh dari empat validator. Tingkat reliabilitas dihitung dengan menggunakan rumus sebagai berikut:

$$
R=\frac{A}{D+A} \times 100 \%
$$

Keterangan:

$\mathrm{A}=$ Frekuensi kecocokan antara penilai (Agree)

$\mathrm{D}=$ Frekuensi ketidakcocokan antara penilai (Disagree)

$\mathrm{R}=$ Reabilitas instrumen (Percentage of Agreement)

Instrumen dikatakan reliabel bila reliabilitas yang diperoleh $\geq 0,75$ (75\%) (Borich, 1994). 2) Analisis empiris instrumen tes meliputi perhitungan validitas butir soal menggunakan rumus korelasi pearson product moment, reliabilitas butir soal menggunakan rumus Alpha Cronbach dan sensitivitas butir soal dari hasil belajar siswa. 3) Analisis tes berpikir kritis dilakukan untuk mengetahui kemampuan berpikir kritis. Seorang siswa dikatakan mampu berpikir kritis bila memperoleh skor $\geq 75 \%$ atau nilai $\geq 75$ (Gronlund, 1981; Majid, 2008). 4) Perbandingan skor pretest dan postest kemampuan berpikir kritis dengan menggunakan gain ternormalisasi dan uji t-berpasangan.

\section{HASIL DAN PEMBAHASAN}

Hasil validasi perangkat pembelajaran oleh para pakar yang terdiri dari Silabus, RPP, LKS dan alat evaluasi merekomendasikan bahwa perangkat tersebut baik dan layak untuk diimplementasikan. Rekomendasi ini berarti bahwa instrumen yang disusun telah sesuai dengan penerapan pembelajaran PBMP-SDL untuk memfasilitasi kemampuan berpikir kritis siswa dan sesuai dengan Peraturan Menteri Pendidikan Nasional Nomor 41 tahun 2007 tentang Standar Proses untuk Satuan Pendidikan Sekolah Dasar dan Menengah. Hasil validasi dapat disajikan dalam Gambar 1.

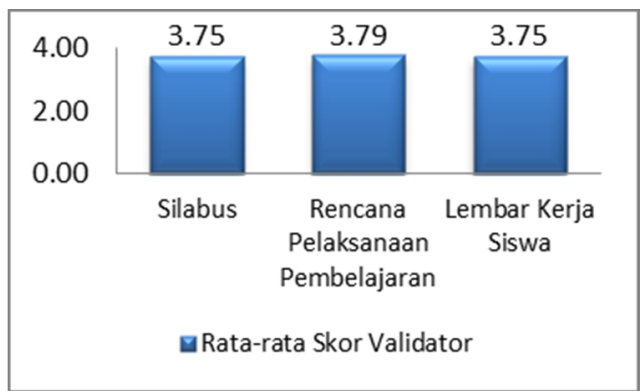

Gambar 1. Grafik Hasil Validasi Perangkat Pembelajaran

Setelah melakukan pengamatan terhadap proses kegiatan belajar mengajar diperoleh hasil seperti yang ditunjukkan pada Tabel 1 di bawah ini.

Tabel 1. Rata-Rata Skor Hasil Pengamatan Keterlaksanaan Pembelajaran: 


\begin{tabular}{|c|c|c|c|c|c|c|}
\hline \multicolumn{2}{|c|}{$\begin{array}{c}\text { Pertemu } \\
\text { an ke - }\end{array}$} & $\begin{array}{c}\text { Penda } \\
\text { huluan }\end{array}$ & $\begin{array}{c}\text { Kegiat } \\
\text { an inti }\end{array}$ & $\begin{array}{c}\text { Penut } \\
\text { up }\end{array}$ & $\begin{array}{c}\text { Rata- } \\
\text { rata }\end{array}$ & $\begin{array}{c}\text { Rel } \\
\text { iabi } \\
\text { lita } \\
\text { s }\end{array}$ \\
\cline { 1 - 5 } $\mathbf{1}$ & $\begin{array}{c}\text { Rata } \\
\text {-rata }\end{array}$ & 4 & 3.9 & 3.5 & 3.8 & \multirow{2}{*}{0.9} \\
\cline { 1 - 5 } $\mathbf{2}$ & $\begin{array}{c}\text { Rata } \\
\text {-rata }\end{array}$ & 4 & 3.9 & 3.3 & 3.8 & 4 \\
& $\begin{array}{c}\text { Rata } \\
\text {-rata }\end{array}$ & 3.8 & 3.8 & 2.5 & 3.6 & \\
\hline
\end{tabular}

Berdasarkan data pada Tabel 1 dapat diketahui bahwa kualitas pelaksanaan pembelajaran yang telah dilakukan adalah baik. Keterlaksanaan pembelajaran yang baik memfasilitasi perolehan penguasaan konsep siswa yang baik pula.

Perhitungan validasi empiris instrumen tes meliputi validitas butir soal, reliabilitas butir soal dan sensitivitas butir soal dari hasil belajar siswa. Berdasarkan hasil perhitungan koefisien korelasi dengan rumus Pearson Product Moment, semua butir soal tes dinyatakan valid. Semua butir soal tes dinyatakan reliabel berdasarkan perhitungan koefisien reliablitas dengan Cronbach Alpha dengan koefisien reliabilitas 0,75 . Nilai koefisien reliabilitas ini termasuk dalam kategori ringgi (Ratumanan, 2006). Koefisien reliabilitas yang semakin tinggi berarti juga tes semakin konsisten (Sukardi, 2004). Semua butir soal yang diujikan memiliki indeks sensitivitas $\geq 0,3$, hal ini menunjukkan bahwa proses pembelajaran telah berlangsung efektif dan tujuan pembelajaran telah tercapai. Hal ini terjadi karena langkah-langkah pembelajaran PBMP-SDL yang terdapat pada RPP telah dilaksanakan dengan baik. Data indeks sensitivitas butir soal ditunjukkan oleh Gambar 2.

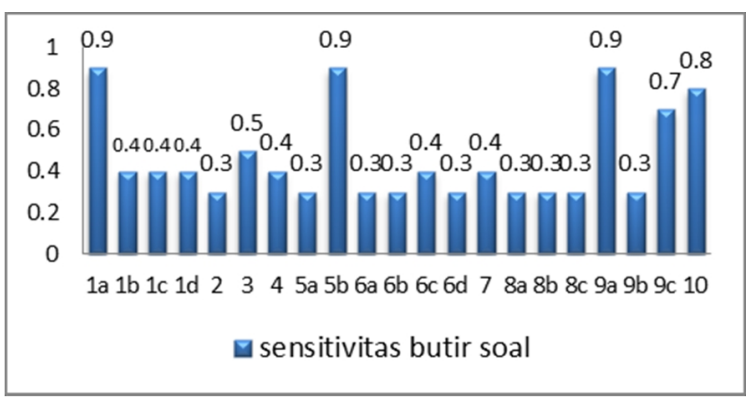

Gambar 2. Grafik Indeks Sensitivitas Butir Soal

Secara umum kemampuan berpikir kritis siswa setelah menggunakan pembelajaran PBMP - SDL mengalami peningkatan. Hal ini dapat dilihat dari skor kemampuan berpikir kritis siswa yang disajikan pada Tabel 2.

Tabel 2. Perbandingan Skor Pretest dan Posttest Kemampuan Berpikir Kritis Siswa

\begin{tabular}{|c|c|c|c|c|c|c|c|}
\hline \multirow[b]{2}{*}{ Nama } & \multicolumn{2}{|c|}{ Skor } & \multirow[b]{2}{*}{$\begin{array}{c}G a i \\
n \\
\text { scor } \\
e\end{array}$} & \multirow[b]{2}{*}{ Nama } & \multicolumn{2}{|c|}{ Skor } & \multirow[b]{2}{*}{$\begin{array}{c}\text { Gain } \\
\text { scor } \\
e\end{array}$} \\
\hline & $\begin{array}{l}\text { Pre } \\
\text { test }\end{array}$ & $\begin{array}{c}\text { Pos } \\
t \\
\text { test }\end{array}$ & & & $\begin{array}{l}\text { Pre } \\
\text { test }\end{array}$ & $\begin{array}{c}\text { Po } \\
\text { st } \\
\text { tes } \\
t\end{array}$ & \\
\hline $\begin{array}{c}\text { siswa - } \\
1\end{array}$ & 51 & 94 & $\begin{array}{c}0.8 \\
8\end{array}$ & $\begin{array}{c}\text { siswa } \\
-18\end{array}$ & 59 & 90 & 0.75 \\
\hline $\begin{array}{c}\text { siswa - } \\
2\end{array}$ & 51 & 85 & $\begin{array}{c}0.7 \\
0\end{array}$ & $\begin{array}{c}\text { siswa } \\
-19\end{array}$ & 73 & 85 & 0.46 \\
\hline $\begin{array}{c}\text { siswa - } \\
3\end{array}$ & 57 & 94 & $\begin{array}{c}0.8 \\
6\end{array}$ & $\begin{array}{c}\text { siswa } \\
-20\end{array}$ & 61 & 71 & 0.25 \\
\hline $\begin{array}{c}\text { siswa - } \\
4\end{array}$ & 63 & 85 & $\begin{array}{c}0.6 \\
1\end{array}$ & $\begin{array}{c}\text { siswa } \\
-21\end{array}$ & 59 & 82 & 0.57 \\
\hline $\begin{array}{c}\text { siswa - } \\
5\end{array}$ & 51 & 81 & $\begin{array}{c}0.6 \\
1\end{array}$ & $\begin{array}{c}\text { siswa } \\
-22\end{array}$ & 55 & 94 & 0.87 \\
\hline $\begin{array}{c}\text { siswa - } \\
6\end{array}$ & 51 & 94 & $\begin{array}{c}0.8 \\
8\end{array}$ & $\begin{array}{c}\text { siswa } \\
-23\end{array}$ & 47 & 82 & 0.67 \\
\hline $\begin{array}{c}\text { siswa - } \\
7\end{array}$ & 63 & 90 & $\begin{array}{c}0.7 \\
2\end{array}$ & $\begin{array}{c}\text { siswa } \\
-24\end{array}$ & 71 & 82 & 0.40 \\
\hline $\begin{array}{c}\text { siswa - } \\
8 \\
\end{array}$ & 61 & 84 & $\begin{array}{c}0.5 \\
9 \\
\end{array}$ & $\begin{array}{l}\text { siswa } \\
-25\end{array}$ & 53 & 79 & 0.56 \\
\hline $\begin{array}{c}\text { siswa - } \\
9\end{array}$ & 61 & 90 & $\begin{array}{c}0.7 \\
4\end{array}$ & $\begin{array}{c}\text { siswa } \\
-26\end{array}$ & 53 & 81 & 0.59 \\
\hline $\begin{array}{c}\text { siswa - } \\
10\end{array}$ & 65 & 96 & $\begin{array}{c}0.8 \\
8\end{array}$ & $\begin{array}{c}\text { siswa } \\
-27\end{array}$ & 39 & 81 & 0.69 \\
\hline $\begin{array}{c}\text { siswa - } \\
11\end{array}$ & 51 & 81 & $\begin{array}{c}0.6 \\
1\end{array}$ & $\begin{array}{c}\text { siswa } \\
-28\end{array}$ & 41 & 82 & 0.70 \\
\hline $\begin{array}{c}\text { siswa - } \\
12\end{array}$ & 51 & 78 & $\begin{array}{c}0.5 \\
5\end{array}$ & $\begin{array}{c}\text { siswa } \\
-29\end{array}$ & 57 & 88 & 0.73 \\
\hline $\begin{array}{c}\text { siswa - } \\
13\end{array}$ & 59 & 82 & $\begin{array}{c}0.5 \\
7\end{array}$ & $\begin{array}{c}\text { siswa } \\
-30\end{array}$ & 59 & 96 & 0.89 \\
\hline $\begin{array}{c}\text { siswa - } \\
14\end{array}$ & 45 & 65 & $\begin{array}{c}0.3 \\
6\end{array}$ & $\begin{array}{c}\text { siswa } \\
-31\end{array}$ & 69 & 82 & 0.44 \\
\hline $\begin{array}{c}\text { siswa - } \\
15\end{array}$ & 51 & 84 & $\begin{array}{c}0.6 \\
7\end{array}$ & $\begin{array}{c}\text { siswa } \\
-32\end{array}$ & 55 & 88 & 0.74 \\
\hline $\begin{array}{c}\text { siswa - } \\
16\end{array}$ & 73 & 97 & $\begin{array}{c}0.8 \\
9\end{array}$ & $\begin{array}{c}\text { siswa } \\
-33\end{array}$ & 47 & 72 & 0.47 \\
\hline $\begin{array}{c}\text { siswa - } \\
17 \\
\end{array}$ & 61 & 84 & $\begin{array}{c}0.5 \\
9\end{array}$ & $\begin{array}{c}\text { siswa } \\
-34\end{array}$ & 59 & 90 & 0.75 \\
\hline & & & & $\begin{array}{l}\text { rata- } \\
\text { rata }\end{array}$ & 55 & 85 & 0.67 \\
\hline
\end{tabular}

Berdasarkan Tabel 2 dapat diketahui bahwa seluruh siswa mengalami peningkatan kemampuan berpikir kritis meskipun dengan skor yang berbeda-beda. Rata-rata skor pretest 55 dan rata-rata skor posttest 85 . Selisih (gain) skor postest dan pretest dengan menggunakan skor gain ternormalisasi didapatkan $<\mathrm{g}>=0,67$ yang artinya hampir mendekati kategori tinggi $(>0,7)$. Prosentase perolehan gain ternormalisasi ditunjukkan grafik pada Gambar 3.

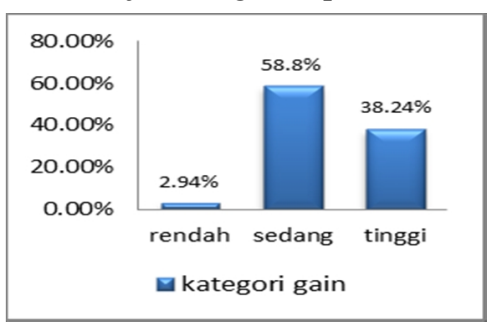

Gambar 5 Grafik Ketuntasan Berpikir Kritis Siswa 
Berdasarkan grafik pada Gambar 5 dapat diketahui bahwa $88,24 \%$ siswa tuntas dan $11,76 \%$ siswa tidak tuntas mencapai indikator berpikir kritis, sehingga secara klasikal siswa dikatakan tuntas dalam berpikir kritis ( $\geq 85 \%)$.

Hasil uji $\mathrm{t}$ berpasangan pada data pretest dan posttest memperoleh Sig (2-tailed) adalah 0,000, hal ini menunjukkan bahwa terdapat perbedaan skor pretest dan posttest yang signifikan, sehingga pembelajaran PBMPSDL yang telah dilakukan mempengaruhi kemampuan berpikir kritis siswa. Hal ini menunjukkan bahwa pembelajaran PBMP-SDL secara signifikan dapat meningkatkan kemampuan berpikir kritis siswa.

Pertanyaan yang diaplikasikan dalam LKS disusun untuk mengarahkan kemampuan berpikir kritis seperti mengidentifikasi, mengklasifikasi, menjawab pertanyaan tentang fakta, memberi alasan jawaban, berargumentasi, membuat hipotesis, membuat kesimpulan, menentukan suatu tindakan, membuat keputusan yang diadaptasi dari Ennis (1985), Glaser (1941) Johnson dan Lamb (2007).

Skor kemampuan berpikir kritis siswa meningkat disebabkan adanya penerapan pembelajaran Pemberdayaan Berpikir Melalui Pertanyaan dengan strategi discovery learning (PBMP-SDL). Perpaduan pembelajaran PBMPSDL dapat meningkatkan penalaran siswa. Perolehan belajar yang baik tersebut diharapkan merupakan refleksi dari penalaran yang baik pula. Hasil penelitian ini sesuai dengan yang dikemukakan oleh Sutikno (2000) yakni secara kualitatif dapat dikatakan bahwa penalaran siswa telah mengalami peningkatan yang berarti melalui pembelajaran dengan PBMP.

Pertanyaan-pertanyaan berperan dapat meningkatkan kemampuan kognitif siswa. Thoe (1998), yang menjelaskan bahwa rangsangan berupa pertanyaan merupakan alat yang dapat dipergunakan untuk meningkatkan kemampuan kognitif siswa. Frazee dan Rudnitski (1995) mengemukakan bahwa salah satu kegunaan terpenting dari pertanyaan adalah untuk memacu keterampilan berpikir tingkat tinggi; yang pada akhirnya hal tersebut sangat menunjang perkembangan penalaran. Seseorang yang mampu berpikir kritis, biasanya juga mempunyai penalaran yang baik. Hal tersebut didukung oleh Alindada (dalam Sumampouw, 2011) yang mengemukakan bahwa cara yang paling mudah untuk menantang pola berpikir kritis adalah dengan pertanyaan-pertanyaan.

Hal ini juga sejalan dengan Bruner yang meyakini bahwa discovery learning merupakan proses belajar di mana guru harus menciptakan situasi belajar yang problematis, mendorong siswa mencari jawaban sendiri, menstimulus siswa dengan pertanyaan-pertanyaan dan melakukan eksperimen, sehingga perpaduan pembelajaran PBMP dan discovery learning pada penelitian ini mampu meningkatkan kemampuan berpikir kritis siswa.
Pola PBMP-SDL merupakan satu pola pembelajaran telah terbukti sangat membantu mengembangkan penalaran siswa karena tidak hanya mengandalkan perolehan konsep dari pengajar, akan tetapi ada upaya untuk memperoleh konsep sendiri; seperti yang diungkapkan oleh Piaget (dalam Dahar, 1988) bahwa pertanyaan-pertanyaan akan mendorong siswa untuk menjawabnya dan termotivasi untuk bekerja keras. Oleh karena itu guru yang menerapkan pembelajaran PBMP-SDL telah membuat informasi menjadi sangat bermakna, dengan memberi kesempatan kepada siswa untuk menemukan dan menerapkan sendiri ide-ide (Nur, 2008).

\section{SIMPULAN}

Berdasarkan Berdasarkan hasil analisis data dan pembahasan dapat disimpulkan bahwa pembelajaran PBMP-SDL berpengaruh secara signifikan dalam meningkatkan kemampuan berpikir kritis siswa.

Berdasarkan temuan penelitian, peneliti memberikan saran-saran sebagai berikut: 1) Mengingat penelitian hanya dilakukan pada materi zat aditif dalam makanan, efektifitas perangkat pembelajaran PBMP-SDL untuk meningkatkan kemampuan berpikir kritis siswa tidak dapat disimpulkan dari penelitian ini saja, namun perlu dilakukan penelitian lebih lanjut yang serupa pada bahan kajian lain. 2) Ciri khas pembelajaran PBMP-SDL adalah pada LKS yang dirancang secara tertulis, oleh karena itu jika ingin menerapkan pembelajaran PBMP-SDL ini guru perlu merancang pertanyaan-pertanyaan yang sesuai dengan karakteristik LKS PBMP-SDL yakni pertanyaan penalaran. 3) Kelemahan pembelajaran PBMP-SDL adalah dibutuhkannya alokasi waktu yang lebih lama, oleh karena itu sebaiknya LKS diberikan pada siswa sebelum pertemuan agar dapat menghemat waktu.

\section{DAFTAR PUSTAKA}

Ahern-Rindell, A.J. 1999. -Applying Inquiry-Based and Cooperative Group Learning Strategis to Promote Critical Thinking. Journal of College Science Teaching, Vol 28 No. 3. pp. 203-207.

Angelo, T. A. 1995. -Classroom Assessment for Critical Thinking. Teaching of Psychology. Vol 22 No 1. February 1995, 6-7.

Arends, R. I. 2012. Classroom Instruction and Management. New York: The McGraw-Hill Companies.

Balm, A. G. 2009. The Effects of Discovery Learning on Students' Success and Inquiry Learning Skillsl. Egitim Arastirmalari-Eurasian Journal of Educational Research. Vol 35. No. 1. pp. 1-20.

Bassham, G., Irwin, W., Nardone, H., Wallace., J.M . 2011. Critical Thinking. Student's Introduction. Fourth 
Edition. New York: The McGraw-Hill Companies, Inc.

Borich, G.D. 1994. Observation Skills for Effective Teaching. Second Edition. New York: Macmillan Company, Inc.

Bruner, J.S. 1967. On Knowing: Essays for The Left Hand. Cambridge, Mass: Harvard University Press.

Bunce, D. M. 1996. -The Quiet Revolution in Science Education-Teaching Science The Way Students Learn. Journal of College Science Teaching. Vol. 25 No. 3. Pp 169-171.

Corebima, A. D., Susilo, H., Sutikno, \& Suhari. 2000. Pemberdayaan Penalaran Pada PBM IPA-Biologi SMP Untuk Menunjang Perkembangan Penalaran Formal Mahasiswa di Jenjang Perguruan Tinggi. Laporan Penelitian Tindakan Kelas Tahun Anggaran 1999/2000. Malang: Lemlit UM Malang.

Corebima, A.D. 2001. Pengembangan Lembar PBMP (TEQ) dalam Pembelajaran IPA - Biologi. Makalah pada Pelatihan dan Lokakarya PBMP bagi Para Guru IPA- Biologi dalam Rangka RUT VII.I 31 Agustus - 1 September 2001 di Biologi FMIPA UM.

Corebima, A.D., Susilo, H., Sutomo, H. 2004. Pengembangan Model Pembelajaran IPA Biologi SMP Konstruktivistik Kontekstual Berorientasi Life Skill dengan Pola PBMP di Kota dan Kabupaten Malang. Laporan Penelitian Akhir Tahun 2004. Kementrian Riset dan Teknologi Lembaga Ilmu Pengetahuan Alam.

Corebima, A.D., Susilo, H., Sutomo, H. 2005. Pengembangan Model Pembelajaran IPA Biologi SMP Konstruktivistik Kontekstual Berorientasi Life Skill dengan Pola PBMP di Kota dan Kabupaten Malang. Laporan Penelitian Akhir Tahun 2005. Kementrian Riset dan Teknologi Lembaga Ilmu Pengetahuan Alam.

Corebima, A.D., Susilo, H., Sutomo, H. 2006. Pengembangan Model Pembelajaran IPA Biologi SMP Konstruktivistik Kontekstual Berorientasi Life Skill dengan Pola PBMP di Kota dan Kabupaten Malang. Laporan Penelitian Akhir Tahun 2006. Kementrian Riset dan Teknologi Lembaga Ilmu Pengetahuan Alam.

Crown, L. W. 1989. - The Nature of Critical Thinking\|. Journal of College Science Teaching. Vol 18 No. 3. pp. 114-116.

Dahar, R.W. 1988. Teori-Teori Belajar. Jakarta: Depdikbud Dirjend Pendidikan Tinggi Proyek Pengembangan Lembaga Pendidikan Tenaga Kependidikan.

Depdiknas. 2008. Panduan Penulisan Butir Soal. Jakarta: Depdiknas.

Elder, L and Paul, R. 2007. -Critical Thinking: The
Nature of Critical and Creative Thought, Part III Journal of Developmental Education. Vol 30 No.3 Spring 2007. pp. $36-37$.

Fisher, A. and Thompson, A. 1993. Testing Reasoning Ability. Center for Research in Critical Thinking, University of East Anglia.

Frazee, B and Rudnitski, R. A. 1995. Integrated Teaching Methods: Theory, Classroom Aplications, and FieldBased Connections. New York : Delmar Publishers.

Gagne, N.L. and Berliner, D.C. 1979. Educational Psychology. Second Edition. Boston: Hougton Miff Lin Company.

Glaser, E. 1941. An Experience in the Development of Critical Thinking. Advanced School of Education at Teacher's College, Columbia University.

Ian J. Q, Brahler, C.J., and Gregory J.C. 2009. - Peer-Led Team Learning: A Prospective Method for Increasing Critical Thinking in Undergraduate Science Courses. Science Educator. Vol. 18 No. 1. Spring 2009. pp. 29 -39 .

Ibrahim, M. 2005. Asesmen Berkelanjutan Konsep Dasar Tahapan Pengembangan dan Contoh. Surabaya: Unesa University Press.

Johnson, L and Lamb, A. 2007. Critical and Creative Thinking- Bloom's Taxonomy. Diakses melalui http://eduscapes.com/tap/topic69.htm pada tanggal 5 September 2011.

Muhfaroyin. 2009. - Pengaruh Strategi Think Pair Share (TPS) dan Kemampuan Akademik terhadap Kemampuan Berpikir Kritis Siswa SMA di Kota Metro. Jurnal Pendidikan dan Pembelajaran. Vol 16 No. 2, Oktober 2009.

Norris, S. and Ennis, R. 1989. Evaluating Critical Thinking. Pacific Grove, CA: Critical Thinking Press and Software.

Nur, M. 2008. Pemotivasian Siswa Untuk Belajar. Surabaya: PSMS UNESA

Nur, M. 2008. Teori-teori Perkembangan Kognitif (Cetakan 3). Surabaya: PSMS UNESA

Peraturan Pemerintah No 19 tahun 2005. Standart Nasional Pendidikan. Jakarta: Depdiknas.

Peraturan Menteri Pendidikan Nasional No 23 Tahun 2006. Standar Kompetensi Lulusan untuk Satuan pendidikan Dasar dan Menengah. Jakarta: Depdiknas.

Peraturan Menteri Pendidikan Nasional No. 41 Tahun 2006. Standar Proses. Jakarta: Depdiknas.

Rehena, J.F. dan Tumbel, F.M. 2010. Strategi Pembelajaran yang Memberdayakan Kemampuan Berpikir Siswall. Kompetensi. Vol 1 No 1 Juli 2010. hal 12 - 19.

Ratumanan, G.T dan Laurens T. 2006. Evaluasi Hasil Belajar yang Relevan dengan Kurikulum Berbasis Kompetensi. Surabaya: Unesa University Press. 
Rosyana, I.I. 2013. Upaya Meningkatkan Keterampilan Berpikir Kritis Siswa Kelas VII-I SMP Al Hikmah Surabaya Melalui Pembelajaran PBMP. Makalah disajikan dalam Seminar Nasional Peran Sains di Abad 21. Universitas Negeri Surabaya, Surabaya, 19 Januari.

Schamel, D., \& Ayres, M. 1992. The Hands-On Approach: Student Creativity and Personal Involvement in the Undergraduate Science Laboratoryll. Journal of College Science Teaching. Vol 21. pp. 226-229.

Snyder, L.G. and Snyder, M.J. 2008. Teaching Critical Thinking and Problem Solving Skills. The Delta Pi Epsilon Journal. Vol 10 No. 2. Spring/Summer. pp. 90 -99 .

Sumampouw, H.M. 2011. Keterampilan Metakognitif dan Berpikir Tingkat Tinggi dalam Pembelajaran Genetika (Artikulasi Konsep dan Verifikasi Empiris)\|. Bioedukasi. Vol 4 No. 2. Agustus 2011. hal 23-39

Undang-Undang Nomor 20 Tahun 2003. Sistem Pendidikan Nasional. Pasal 3. Jakarta: Depdiknas.

Woods, D. R. 1996. Teaching and Learning: What Can Research Tell Us?. Journal of College Science Teaching. Vol 25 No. 3. pp. 229-232.

Yager, R. E. and Huang, D. 1994. An Alternative Approach to College Science Education for Nonscience Majorsll. Journal of College Science Teaching, Vol 23 No. 3. pp. 98-100.

Zubaidah, S., Sunarmi, Prasetyo, T.I. 2001. Penerapan Pola PBMP (Pemberdayaan Berpikir Melalui Pertanyaan) pada Matakuliah Botani Tumbuhan Rendah untuk Menunjang Perkembangan Penalaran Formal Mahasiswa. Malang: Lemlit UM. 